\title{
Bromate incorporation in calcite and aragonite
}

\author{
Scott D. Midgley, ${ }^{a}$ Dominik Fleitmann, ${ }^{\text {b,c }}$ Ricardo Grau-Crespo ${ }^{\text {a* }}$ \\ ${ }^{a}$ Department of Chemistry, University of Reading, United Kingdom, RG6 6DX, United Kingdom. Email: r.grau-crespo@ reading.ac.uk \\ ${ }^{b}$ Department of Archaeology, University of Reading, United Kingdom, RG6 6AB, United Kingdom. \\ ${ }^{c}$ Department of Environmental Sciences, University of Basel, Switzerland.
}

\begin{abstract}
The presence of bromine as a trace-element in calcium carbonate speleothems constitutes a useful proxy of past volcanic activity, thus helping to provide input parameters for climate model simulations and risk assessment. However, the chemical nature of bromine-containing impurities in the calcium carbonate phases forming speleothems is not understood, which limits interpretation of experimental measurements on speleothems. We present here a computer simulation study, based on quantum mechanical calculations, of the incorporation of bromine as $\mathrm{BrO}_{3}^{-}$oxyanions in $\mathrm{CaCO}_{3}$ polymorphs calcite and aragonite. We discuss how the relative distribution of bromate anions and charge-compensating alkali-metal cations is determined by the interplay between an impurity binding effect (which is stronger for aragonite than for calcite, and changes in the order $\mathrm{Li}<\mathrm{Na}<\mathrm{K}$ ) and a configurational entropic effect that tends to disassociate the impurities. For concentrations above parts-permillion, bromate impurities can be expected to be paired, in nearest-neighbour configurations, with the compensating cations. Bromate substitution, compensated by sodium or potassium cations, is predicted to be metastable with respect to phase separation of the impurities as solid $\mathrm{NaBrO}_{3}$ or $\mathrm{KBrO}_{3}$ phases, respectively, but the solubility limits of $\mathrm{BrO}_{3}{ }^{-}$in calcite and aragonite are still higher than those calculated for tetrahedral oxyanions $\left(\mathrm{SO}_{4}\right)^{2-}$ and $\left(\mathrm{MoO}_{4}\right)^{2-}$ that are used as alternative volcanic records in speleothems.
\end{abstract}

Keywords: calcium carbonate, calcite, aragonite, bromate. 


\section{Introduction}

Volcanic eruptions impact local and global climates (Robock, 2000; Sigl et al., 2013; Zielinski, 2000). In particular, they have been shown to significantly disrupt transfer of solar radiation, leading to a cooling effect that can affect large areas of the planet for several years and possibly even for decades (Minnis et al., 1993; Robock and Free, 1995). Recent research efforts have attempted to build accurate reconstructions of volcanic activity spanning millennia, to understand the historical impact of these significant geological events on global climate. Though instrumental and historical records of volcanic activity exist for a few centuries, obtaining information on volcanic eruptions further back in time requires analysis of naturally occurring archives to reveal the explosive history of volcanoes. Ice-cores (Severi et al., 2012; Yalcin et al., 2007; Zielinski et al., 1994), tree rings (McCarroll and Loader, 2004) and marine sediments (Voelker, 2002) are all well-established records of volcanic activity in the past, because they provide a naturally undisturbed environment in which geochemical tracers and tephra layers may be preserved over long timescales. Proxies contained within these geological archives, such as trace-element concentrations (Hartland et al., 2012) and $\delta^{18} \mathrm{O}$ isotopic composition (Marshall et al., 2009) have been used to derive valuable information about past climate and compositions of the atmosphere. Speleothems are another example of such an archive, and have begun to show increasing promise as paleovolcanic records in recent years (Badertscher et al., 2014; Fairchild and Treble, 2009; Finch et al., 2001; Ünal-İmer et al., 2015). Speleothems have two key advantages over the use of ice-cores, which are one of the key archives for paleoclimate research. The first is that speleothem formation is not linked to the low temperatures associated with high latitudes. This is important as many of the most explosive volcanoes are located in the tropics and subtropics and, thus, far away from the polar ice cores. The second advantage is that the uranium-thorium dating technique is well established for calcium carbonates, meaning that accurate speleothem dating is relatively straightforward (Dorale et al., 2004; St Pierre et al., 2009). Calcite is the most stable calcium carbonate phase over long geological timescales, and it comprises the majority of speleothems. Aragonite is meta-stable under some geochemical conditions, and forms speleothems in some rarer cases (De Choudens-Sanchez and Gonzalez, 2009; Given and Wilkinson, 1985; Railsback et al., 1994).

Major volcanic eruptions affect the chemical composition of the atmosphere and pedosphere (soil layers). Elements such as sulphur, molybdenum and bromine are known to be in high relative abundance following an eruption, and these may eventually become incorporated as impurities into the structures of speleothems. However, little is known about the chemical nature of these species in speleothem carbonate minerals. Recent computer modelling research by our group has considered the thermodynamics of sulphate and molybdate incorporation in speleothems, finding that bulk lattice incorporation of these anions is thermodynamically unfavourable, owing to significant elastic strain on the crystal caused by the large, tetrahedral anion geometries (Midgley et al., 2020), and that surfaces (or more accurately, the mineral-water interface) provide a more favourable environment for hosting the oxyanion impurities, especially in the presence of surface defects (Midgley et al., 2021). 
We extend here our computational studies to the investigation of bromine incorporation in calcite and aragonite. (Badertscher et al., 2014) have argued that bromine is probably the most effective speleothem-based paleovolcanic proxy among those investigated so far. Its fast leaching through soil layers made it detectable in speleothems found in the Sofular cave, within +/- 1-2 years of the Minoan eruption that occurred in Northern Turkey at around 1621 BCE (Friedrich et al., 2006). Very little is known about how bromine incorporates in calcium carbonate minerals. Elevated quantities of bromine in the form of hypobromite $(\mathrm{BrO})$ are dumped into the local environment following a major volcanic eruption (Bobrowski et al., 2003; Hörmann et al., 2013; Theys et al., 2009). Hypobromite has been shown to play a critical role in tropospheric and stratospheric chemistry, with ozone depletion known to be a significant environmental consequence of this species if airborne. Its stability with respect to oxidation to bromate is low under most conditions (Engel and Perlmutter-Hayman, 1953; Lee and Lister, 1971). It is therefore reasonable to assume that incorporation of bromine in speleothems occurs in the form of the monovalent anion bromate, $\left(\mathrm{BrO}_{3}\right)^{-}$, in analogy with the incorporation of iodine as iodate, $\left(\mathrm{IO}_{3}\right)^{-}$, in calcium carbonate minerals (Feng and Redfern, 2018; Kerisit et al., 2018; Podder et al., 2017).

Bromate has a trigonal pyramidal geometry due to the presence of a lone pair, and therefore it is not an ideal fit to substitute the trigonal planar carbonate $\left(\mathrm{CO}_{3}{ }^{2-}\right)$ anion. However, its flatter shape in comparison with that of tetrahedral oxyanions sulphate $\left(\mathrm{SO}_{4}\right)^{2-}$ and molybdate $\left(\mathrm{MoO}_{4}\right)^{2-}$ may allow easier lattice substitution. The chemistry of the aliovalent bromate/carbonate substitution is different from that of the isovalent molybdate/carbonate or sulphate/carbonate substitutions, and the charge compensating mechanisms can be expected to play a significant role in the thermodynamics of bromate incorporation. (Kerisit et al., 2018) indeed found that, in the case of iodate substitution in calcite, there is an energetic preference for the compensating cation $\left(\mathrm{H}^{+}\right.$or $\mathrm{Na}^{+}$in their study) to be placed near the iodate impurity. The ease of incorporation also depends on the host carbonate phase, and (Feng and Redfern, 2018) found that iodate can incorporate into crystalline bulk calcium carbonate with increasing difficulty in the order vaterite, calcite and aragonite, following the relative density of these phases.

In the present paper we use first principles simulation techniques to investigate for the first time the incorporation of bromate in calcite and aragonite (as the phases most interesting for our understanding of speleothems), and the relative distribution of bromate anions and compensating cations in both phases. We will report the thermodynamic parameters describing the ease of incorporation in each case, both with respect to isolated ions and to competing phases. We will discuss the impurity distribution problem in terms of two thermodynamic driving forces: the binding energy between the two oppositely charged impurity defects that tends to keep the impurities paired, and the configurational entropy effects that favour unpaired impurities at low concentrations.

\section{Computational methods}

Computer simulations within the density functional theory (DFT) were performed using the VASP code (Kresse and Furthmüller, 1996a, b), under the generalized gradient approximation (GGA) in the form of the PBE 
exchange-correlation functional (Perdew et al., 1996). The projector augmented wave (PAW) method (Blöchl, 1994; Kresse and Joubert, 1999) was used to describe the interaction between valence electrons and the core. The number of plane waves used in the basis was determined by a kinetic energy cutoff of $520 \mathrm{eV}$, which is $30 \%$ above the recommended value for the set of PAW potentials used, to minimize Pulay stress errors.

Calcite has a trigonal crystal system and a space group of R-3c (No. 167) (Markgraf and Reeder, 1985), and was modelled here using a hexagonal $3 \times 3 \times 1$ supercell ( 54 formula units of $\mathrm{CaCO}_{3}$ ) as shown in Figure 1a. Aragonite is orthorhombic with the space group Pmon (No. 62) (De Villiers, 1971), and was modelled using a $3 \times 2 \times 3$ supercell ( 72 formula units; Figure 1b). The use of relatively large supercells is needed to maximise the distance between each impurity and its periodic images (at least $\sim 15 \AA$ apart), as well as to explore the configurational space of relative positions of cation and anion impurities. The symmetrically inequivalent substitution configurations were obtained using the methodology implemented in the Site Occupancy Disorder program (SOD) (Grau-Crespo et al., 2007), which has been useful before in the investigation of impurity distribution in carbonate minerals (González-López et al., 2014; Ruiz-Hernandez et al., 2010; Wang et al., 2011). Two configurations are equivalent if they are related by a symmetry operator of the parent (unsubstituted) crystal structure. Each configuration was relaxed to full geometry optimization in VASP, and the final energies were used for statistical analysis of the impurity distribution.
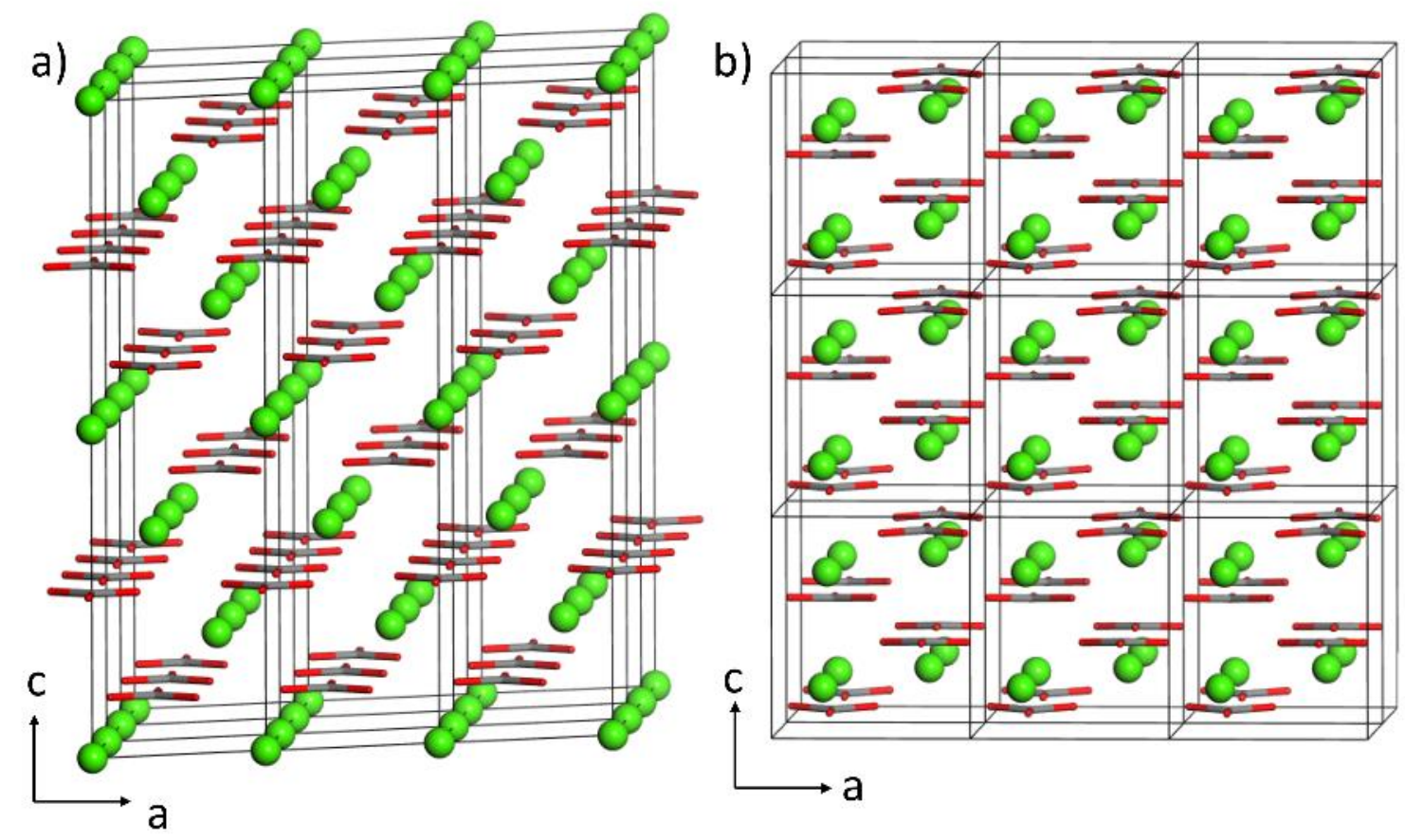

Figure 1. Supercells of a) calcite $(3 \times 3 \times 1)$ and b) aragonite $(3 \times 2 \times 3)$ employed in this work. Colour code: $\mathrm{Ca}=$ green; $\mathrm{C}=$ grey; $\mathrm{O}=$ red. 
The SOD/VASP analysis elucidated the minimum energy configuration of $\mathrm{MBrO}_{3}$ in calcite and aragonite, which was always the proximal ion-pair configuration. To calculate the energy of $\mathrm{CaCO}_{3} / M \mathrm{BrO}_{3}$ substitution in calcite, we computed two sets of energy values. The first we call the ion exchange energy $E_{\text {exch }}$, and is the energy of exchanging $\mathrm{Ca}^{2+}$ and $\mathrm{CO}_{3}{ }^{2-}$ ions from the bulk calcium carbonate structure with $M^{+}$and $\mathrm{BrO}_{3}{ }^{-}$ ions from vacuum:

$$
\begin{gathered}
\left.\Delta E_{\text {exch }}=E\left[\mathrm{Ca}_{n-1} M\left(\mathrm{CO}_{3}\right)_{n-1} \mathrm{BrO}_{3}\right]\right]+\left(E\left[\left(\mathrm{Ca}^{2+}\right)_{\mathrm{gas}}\right]+E\left[\left(\mathrm{CO}_{3}^{2-}\right)_{\mathrm{gas}}\right]\right)-E\left[\mathrm{Ca}_{n}\left(\mathrm{CO}_{3}\right)_{n}\right] \\
+\left(E\left[\left(M^{+}\right)_{\mathrm{gas}}\right]+E\left[\left(\mathrm{BrO}_{3}^{-}\right)_{\mathrm{gas}}\right]\right)
\end{gathered}
$$

where $E\left[\mathrm{Ca}_{n-1} M\left(\mathrm{CO}_{3}\right)_{n-1} \mathrm{BrO}_{3}\right]$ is the energy of the calcium carbonate supercell containing one $\left(M^{+}+\mathrm{BrO}_{3}^{-}\right)$ substitution, $E\left[\mathrm{Ca}_{n}\left(\mathrm{CO}_{3}\right)_{n}\right]$ is the energy of the pure calcium carbonate supercell, $E\left[\left(M^{+}\right)_{\mathrm{gas}}\right]$ and $E\left[\left(\mathrm{BrO}_{3}{ }^{-}\right)_{\mathrm{gas}}\right] /$ $E\left[\left(\mathrm{CO}_{3}{ }^{2-}\right)_{\text {gas }}\right]$ are the energies of the isolated ions. This analysis allows for comparison between cation substitutions within the same carbonate phase, and comparison of the same cation substitution between carbonate phases. As these calculations are benchmarked against the arbitrary referece of ions in vacuum, the absolute values of these energies carry no physical meaning. The purpose of $E_{\text {exch }}$ is to provide a common reference point for comparison of energies between each of the systems examined.

To calculate $\mathrm{Ca}^{2+}+\mathrm{CO}_{3}{ }^{2-}$ and $M^{+}+\mathrm{BrO}_{3}^{-}$as isolated ions in vacuum, within the context our periodic DFT calculations, we calculated the energy of the ion pair in the limit of an infinitely large cell. Models were created where the cation was placed in the centre of the cell and the anion was placed at the corner of the cell. The cell was expanded from $a=4 \AA$ to $a=28 \AA$ in $4 \AA$ increments. We plotted $1 / a$ vs energy as shown in Figure 2 below. In each case, the $y$-intercept of the linear relationship shown corresponds to the energy of the noninteracting ion pair in an infinitely large cell.

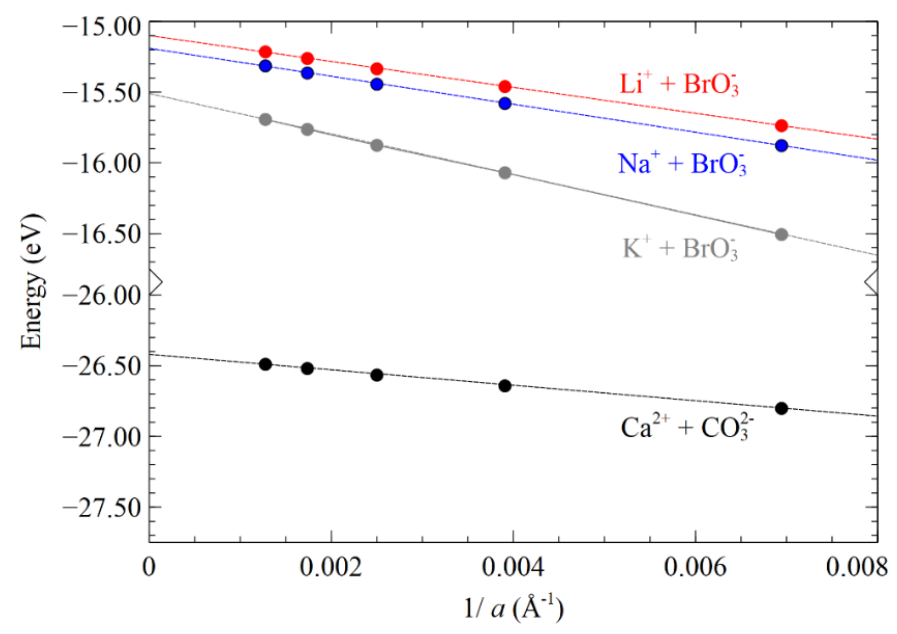

Figure 2. Determination of the energy of separated anion-cation pairs: the energy per cell of a periodic system containing one cation at the origin and one anion at the centre of the cell is plotted vs the inverse of the lattice parameter $a$, keeping interatomic distances constant within the oxyanion. The linear extrapolation when $1 / a$ tends to zero gives the energy of the pair at infinite separation. 
To assess the stability of bromate species in the calcium carbonate phases, we also calculated the solution energies, $E_{\mathrm{sol}}$, which are relative to the thermodynamic competing phase (sodium bromate or potassium bromate):

$$
\Delta E_{\text {sol }}=E\left[\mathrm{Ca}_{n-1} M\left(\mathrm{CO}_{3}\right)_{n-1} \mathrm{BrO}_{3}\right]-(n-1) E\left[\mathrm{CaCO}_{3}\right]-E\left[M \mathrm{BrO}_{3}\right]
$$

where $E\left[\mathrm{CaCO}_{3}\right]$ is the energy per formula unit of the pure calcium carbonate, and $E\left[M \mathrm{BrO}_{3}\right]$ is the energy per formula unit of the competing phase: sodium bromate and potassium bromate. As pure $\mathrm{LiBrO}_{3}$ is not known, we have excluded lithium from consideration here. The absolute magnitude of the solution energy calculated in this way is more physically meaningful. However, since the $\Delta E_{\text {sol }}$ energies are not calculated with respect to a common reference, they should not be used for comparison across different polymorphs or compensating cations.

\section{Results}

For calcite we found 11 inequivalent configurations of one cation/anion pair substitution per supercell, whereas in the aragonite supercell the number of inequivalent configurations is 48. The energies of each configuration in calcite, after full geometry optimisations, are reported in Table 1. They are given relative to the overall lowest total energy configuration, which is configuration 1 in each case and corresponds to the nearest-neighbour anioncation configuration.

Table 1: Energies of $M^{+}+\left(\mathrm{BrO}_{3}\right)^{-}$incorporation in calcite $(M=\mathrm{Li}$, $\mathrm{Na}$ and $\mathrm{K})$, relative to the configuration with nearestneighbour pairing.

\begin{tabular}{lllll}
\hline Configuration & $d_{\min }\left(\mathrm{Br}-M^{+}\right)(\AA)$ & $E_{\mathrm{Li}}(\mathrm{eV})$ & $E_{\mathrm{Na}}(\mathrm{eV})$ & $E_{\mathrm{K}}(\mathrm{eV})$ \\
\hline 1 & 3.25 & 0.00 & 0.00 & 0.00 \\
2 & 4.31 & 0.60 & 0.40 & 0.24 \\
3 & 6.00 & 0.51 & 0.29 & 0.08 \\
4 & 6.64 & 0.57 & 0.39 & 0.24 \\
5 & 6.64 & 0.43 & 0.28 & 0.08 \\
6 & 7.74 & 0.63 & 0.43 & 0.27 \\
7 & 7.85 & 0.56 & 0.36 & 0.21 \\
8 & 9.24 & 0.59 & 0.40 & 0.25 \\
9 & 9.75 & 0.59 & 0.40 & 0.25 \\
10 & 9.75 & 0.59 & 0.41 & 0.28 \\
11 & 10.56 & 0.63 & 0.36 & 0.28 \\
\hline
\end{tabular}

In Table 1, $d_{\min }$ represents the minimum distance between $\mathrm{Br}$ and $M$ before relaxation (i.e. between the $\mathrm{C}$ and the $\mathrm{Ca}$ atoms being substituted in the pure calcite structure). Where the anion-cation distance is the same in 
more than one case (configurations $4 \& 5$ and $9 \& 10$ ), the configurations are still symmetrically inequivalent by virtue of the oxygen atoms, and in these cases, anion-cation distances diverge following structural relaxation.

The binding energies $(\varepsilon)$ between the impurities, calculated as the difference between the lowest and highest energies in the configurational spectrum, are shown in Table 2 together with the exchange energies for each host phase and compensating cation, calculated using Eq. (1) under the assumption that the bromate anions and the compensating cations are in relative $\mathrm{NN}$ positions.

Table 2. Binding energies $(\varepsilon)$ between oppositely charged impurity defects, and ion exchange energies $\left(\Delta E_{\text {exch }}\right)$ for calcite and aragonite assuming impurity pairing in nearest-neighbour positions.

\begin{tabular}{|c|c|c|c|c|}
\hline \multirow{2}{*}{$\begin{array}{c}\text { Compensating } \\
\text { cation }\end{array}$} & \multicolumn{2}{|c|}{ calcite } & \multicolumn{2}{|c|}{ aragonite } \\
\hline & $\Delta E_{\text {exch }}(\mathrm{eV})$ & $\varepsilon(\mathrm{eV})$ & $\Delta E_{\text {exch }}$ & $\varepsilon(\mathrm{eV})$ \\
\hline $\mathrm{Li}^{+}$ & 5.59 & 0.63 & 5.38 & 1.08 \\
\hline $\mathrm{Na}^{+}$ & 6.42 & 0.43 & 6.31 & 0.62 \\
\hline $\mathrm{K}^{+}$ & 7.33 & 0.28 & 6.95 & 0.54 \\
\hline
\end{tabular}

Table 3 list solution energies, calculated using Equation 2. Solution energies provide thermodynamic insight into formation energy with respect to the competing phase, for example sodium bromate $\left(\mathrm{NaBrO}_{3}\right)$ or potassium bromate $\left(\mathrm{KBrO}_{3}\right)$. Here the correct procedure is to evaluate the energy of the energy of the mixed system in the absence of NN pairing, because as we will show below, solubility limits (shown as $x_{\mathrm{m}}$ in Table 3) are well below the pairing threshold.

Table 3. Solution energies $\left(\Delta E_{\mathrm{sol}}\right)$ and solubility limits $\left(x_{\mathrm{m}}\right)$ for alkali metal-compensated bromate substitution in calcite and aragonite.

\begin{tabular}{lllll}
\hline & \multicolumn{2}{c}{ calcite } & \multicolumn{2}{c}{ aragonite } \\
\hline Competing phase & $\Delta \boldsymbol{E}_{\text {sol }}(\mathbf{e V})$ & $\boldsymbol{x}_{\mathbf{m}}$ & $\boldsymbol{\Delta} \boldsymbol{E}_{\text {sol }}(\mathbf{e V})$ & $\boldsymbol{x}_{\mathbf{m}}$ \\
$\mathrm{NaBrO}_{3}$ & 1.41 & $2 \times 10^{-12}$ & 1.71 & $5 \times 10^{-15}$ \\
$\mathrm{KBrO}_{3}$ & 1.79 & $1 \times 10^{-15}$ & 1.88 & $2 \times 10^{-16}$ \\
\hline
\end{tabular}

\section{Discussion}

There is a clear energy difference between the configuration with nearest-neighbouring impurities and the rest (Table 1), whereas the energy differences between the rest of the configurations are smaller. This is illustrated in Figure 3, for the case of bromate/lithium substitution in calcite. The energy distribution across the configurations can be roughly approximated as a sharp drop in energy (the binding energy) at nearest neighbour 
position, and a constant energy for all the other configurations. This behaviour is observed for both calcite and aragonite (the latter not shown in a table due to the much larger number of configurations). The binding energies ( $\varepsilon$ ) between the impurities follow the trends $\mathrm{Li}>\mathrm{Na}>\mathrm{K}$, and aragonite> calcite, which we will attempt to rationalise below.

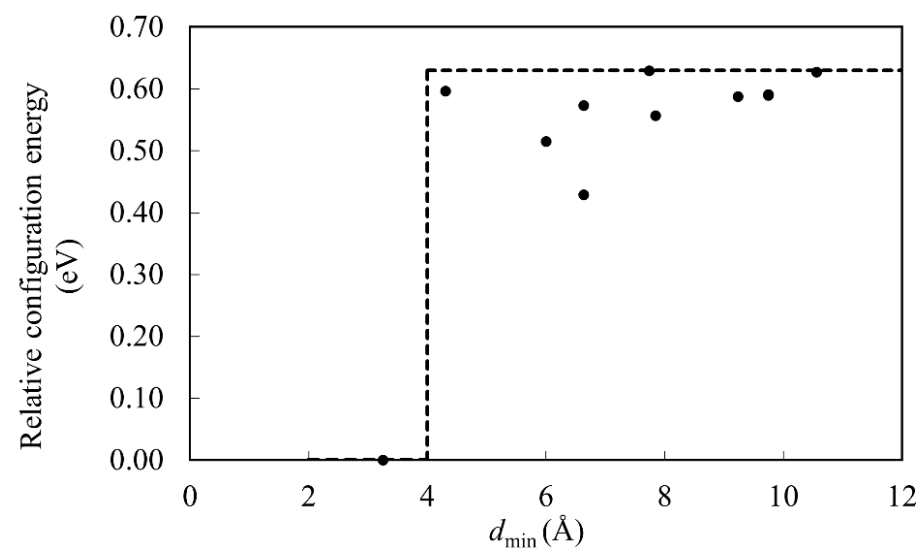

Figure 3. Plot of $E$ vs $d_{\min }$ in the configurational space of bromate and lithium substituted calcite.

This simple "binding energy" approximation is useful for a discussion of the probability of nearest-neighbour pairing of bromates and compensating cations, based on statistical mechanics. Let us consider a very large supercell of $n \mathrm{CaCO}_{3}$ formula units, where we introduce one cation and one anion substitution, in such a way that the molar fraction of substitution is $x=1 / n$. This supercell can be in one of two states: the binding or pairing state, where the cation and anion substitution form a nearest-neighbour $(\mathrm{NN})$ pair, which has energy $-\varepsilon$ and degeneracy $z n$ (where $\varepsilon$ is the binding energy between the oppositely charged substitutions, and $z$ is the coordination number between $\mathrm{NN}$ pairs); and the non-binding state, where the cation and anion substitutions are not in NN positions, which has energy zero and degeneracy $n^{2}-z n$. Using a Boltzmann's canonical distribution, the probability of $\mathrm{NN}$ pairing is then:

$$
P_{\text {pair }}=\frac{z n \exp \left(\frac{\varepsilon}{k_{\mathrm{B}} T}\right)}{z n \exp \left(\frac{\varepsilon}{k_{\mathrm{B}} T}\right)+n(n-z)}=\frac{1}{1+\left(\frac{1}{z x}-1\right) \exp \left(-\frac{\varepsilon}{k_{\mathrm{B}} T}\right)}
$$

where $k_{\mathrm{B}}$ is Boltzmann's constant and $T$ is the absolute temperature of equilibration. The above expression is consistent with the equation for energy-dependent site occupancy derived by (Catlow, 1978). In principle it is possible to use a more sophisticated numerical approach, going beyond the minimal supercell to take into account mutual siting of many pairs (Smith et al., 2010), but the more approximate treatment is sufficient here to elucidate the pairing trends. In the limit of strong binding $\left(\varepsilon>>k_{\mathrm{B}} T\right)$ and not very low concentration $x$, the probability of pairing tends to 1, i.e. each substituted cation has a substituted anion in NN position. On the other hand, when the concentration of substitutions is very low, the probability is simply linear on $x$ : 


$$
P_{\text {pair }} \approx z x \exp \left(\frac{\varepsilon}{k_{\mathrm{B}} T}\right)
$$

The probabilities of pairing at ambient temperature $T=300 \mathrm{~K}$ as function of impurity concentration for each phase and compensating cation are shown in Figure 4. At very low concentrations the probability of pairing increases linearly with $x$ following Eq (4). Above certain threshold concentrations, the pairing probability saturates at 1 , which means that all impurity pairs will be found in nearest neighbour configurations. For calcite, these threshold concentrations are $\sim 10^{-11}$ for $\mathrm{Li}, \sim 10^{-7}$ for $\mathrm{Na}$, and $\sim 10^{-5}$ for $\mathrm{K}$. For aragonite, the corresponding threshold concentrations for pairing are even lower, following the same trend $(\mathrm{Li}>\mathrm{Na}>\mathrm{K})$ with the nature of the compensating cation.

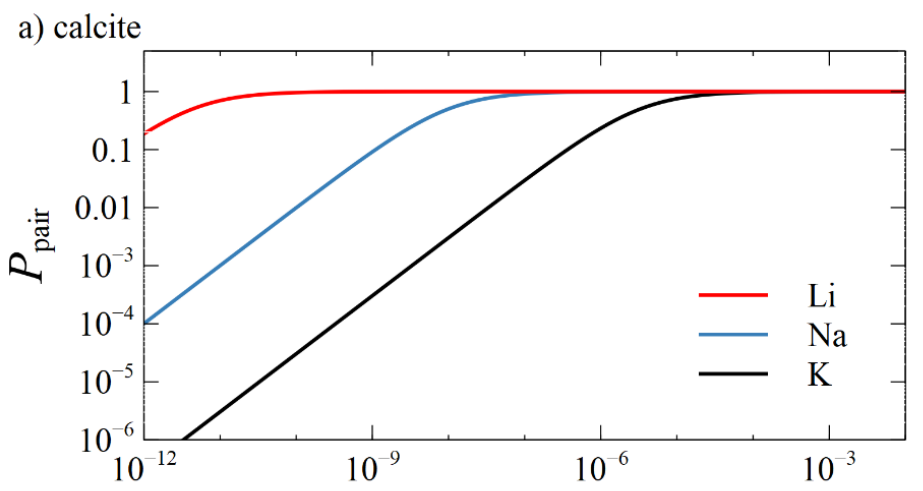

b) aragonite

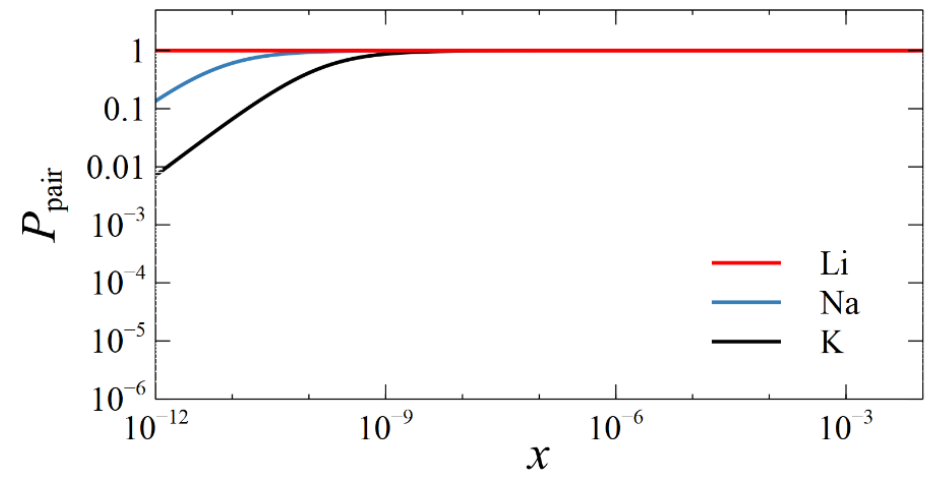

Figure 4. Pairing probability $P_{\text {pair }}$ vs impurity $\left(M^{+}+\mathrm{BrO}_{3}{ }^{-}\right.$, where $M=\mathrm{Li}$, Na, or K) concentration $x$ at ambient temperature for a) calcite b) aragonite.

Precise bromate concentrations in naturally occurring speleothems are not reported in the literature. The most commonly studied trace element, sulphur, is known to appear in a range of concentrations from roughly 10 to 40 ppm (Frisia et al., 2008) following volcanic activity, though this figure could vary dramatically depending on magnitude of volcanic eruption. Marine carbonates have been shown to take up sulphate in the order of $10^{3} \mathrm{ppm}$, two orders of magnitude higher than in speleothem archives (Busenberg and Niel Plummer, 1985). Our analysis above suggests that for concentrations of impurities in the order of several ppm, bromate impurities can be expected to be located in the immediate vicinity of a compensating cation. 
The absolute values of the exchange energies reported in Table 2 are irrelevant, with the very high values mainly reflecting the loss of electrostatic stability associated with the aliovalent substitutions, when the isolated ions are taken as reference. But the trends across different cations and host phases are interesting. Compensated bromate incorporation in aragonite is slightly favoured over incorporation in calcite, which is somewhat unexpected given that aragonite is a denser phase than calcite. This is in contrast with the behaviour observed for isovalent substitution of carbonates by tetrahedral oxyanions (Midgley et al., 2020), where elastic effects, and therefore density, was the primary driver of increased exchange energy.

The stability of the double substitution (anion + cation) is controlled by two factors: 1) a significant favourable electrostatic stabilisation is gained when the distance between the substituting ions is minimised; 2) an unfavourable elastic (lattice) strain energy that comes from distortion of the host crystal, this is particularly unfavourable when the distortion is accumulated in a small region of the crystal, i.e. when the ions are in a proximal configuration. Comparing the impurity binding energies of aragonite and calcite with the corresponding exchange energy differences, indicates that the main reason for a lower exchange energy in aragonite is the stronger binding energy between the two impurities. The binding energy is greater in aragonite because the higher phase density affords a shorter anion-cation distance, which is around $2.9 \AA$ in aragonite and $3.2 \AA$ in calcite, prior to structural relaxation. On the other hand, the higher density of aragonite also increases the elastic strain effects, which explains why the exchange energies for aragonite are still similar to those for calcite. The strain effects on the local structures around the impurities are illustrated in Figures $\mathbf{5}$ for calcite and in Figure $\mathbf{6}$ for aragonite. After relaxation, there is significant ionic reorganisation in aragonite, while in calcite ions occupy the lattice sites of calcium and carbonate without much distortion.

Another trend seen in Table $\mathbf{2}$ is the increasing substitution energy with increasing cation radius. This may be explained by considering the increased elastic strain imparted on the host crystal when incorporating a larger cation. In the case of $\mathrm{K}^{+}$compensation, in addition to the relatively high elastic cost of inserting a large cation, there is a reduction in the binding energy stabilization, due to the combined effect of the distortion fields of both substitutions. It is therefore likely that in geochemical environments, smaller cations are more favourable for charge compensation mechanisms. 


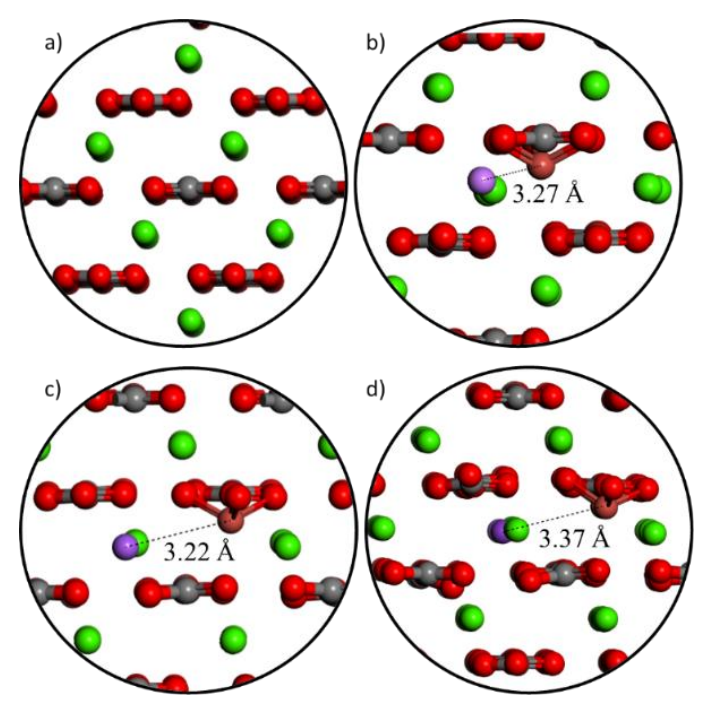

Figure 5. Optimized local geometries around the double substitution of $M^{+}$and $\left(\mathrm{BrO}_{3}\right)^{-}$into calcite where a) is pure calcite and the others are bromate-substituted compensated by b) $M=\mathrm{Li}$ c) $M=\mathrm{Na}$ d) $M=\mathrm{K}$.

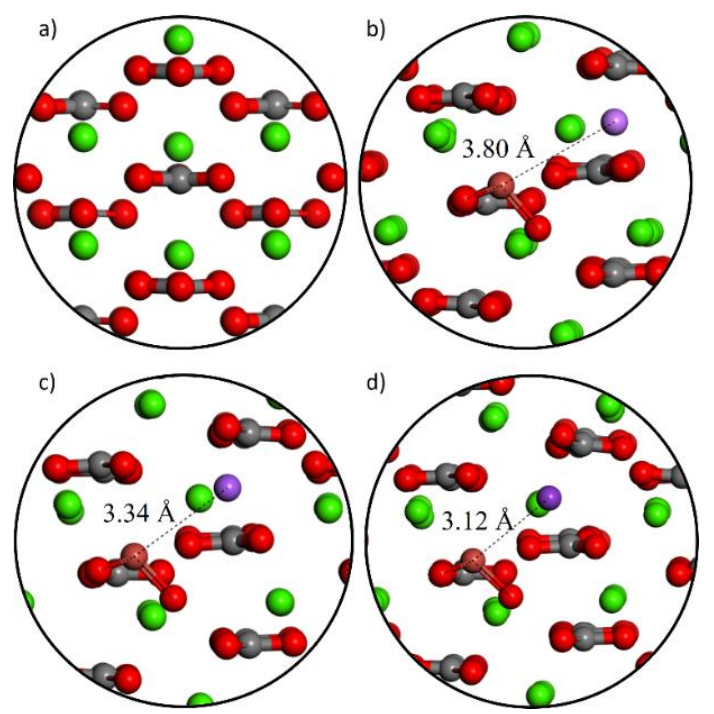

Figure 6: Optimized local geometries around the double substitution of $M^{+}$and $\left(\mathrm{BrO}_{3}\right)^{-}$into aragonite where a) is pure aragonite and the others are bromate-substituted compensated by b) $M=\mathrm{Li}$ c) $M=\mathrm{Na}$ d) $M=\mathrm{K}$.

Finally, we discuss the implications of the calculated solution energies, presented in Table 3. Whether a certain level of trace impurity incorporation is stable or not with respect to separation into a competing phase depends on the balance between the enthalpy of mixing

$$
\Delta H_{\mathrm{mix}} \approx x \Delta E_{\mathrm{sol}}
$$

and the configurational entropy effect:

$$
-T S_{\text {conf }}=2 k_{\mathrm{B}} T[x \ln x+(1-x) \ln (1-x)]
$$


that stabilises the mixing. The factor of 2 in eq. (6) appears because there are two independently disordered species with concentration $x$ (when the concentration is well below the pairing threshold). As in previous work (Grau-Crespo et al., 2011; Midgley et al., 2020) the solubility limit or maximum concentration of impurity thermodynamically stable against phase separation can therefore be estimated from the solution energy:

$$
x_{\mathrm{m}} \approx \exp \left(-\frac{\Delta E_{\mathrm{sol}}}{2 k_{\mathrm{B}} T}\right)
$$

For Na-compensated bromate substitution in calcite, this value is $\sim 2 \times 10^{-12}$, and for the same substitution in aragonite is $\sim 5 \times 10^{-15}$. The values for K-compensated substitutions are even lower (see Table 3). The low values suggest that bromate substitution at ppm level and even at ppb level in bulk lattice sites is metastable with respect to phase separation, at least when compensated by $\mathrm{Na}$ or $\mathrm{K}$. This conclusion should be accompanied by some caveats. First, the solubility limits via other charge compensating schemes (e.g. with $\mathrm{Li}^{+}$, or even $\mathrm{H}^{+}$which has not been considered here) might be much higher, leading to thermodynamically stable bromate substitution. Second, metastable bulk incorporation can still occur due to the complicated kinetics of mineral growth. For example, it is known that sulphate can partially incorporate in the bulk of calcite, even if the calculated solubility limits obtained for sulphate (Midgley et al., 2020) are very low (in fact much lower than the solubility limits obtained here for bromate). The higher solution limit of bromate compared to sulphate and molybdate is mainly due to the lower strain around the oxyanion impurity when the fourth, apical oxygen is not present, even if the trigonal pyramidal bromate ion is not a perfect fit to substitute the trigonal planar carbonate anion.

\section{Conclusions}

We have presented a computer simulation study of the incorporate of bromate ions as aliovalent substitutional impurities in the anion sites of calcium carbonate minerals calcite and aragonite. The chemistry associated to the incorporation of these species is more sophisticated than that of isovalent substitutions of carbonate by sulphate or molybdate, that we investigated previously (Midgley et al., 2021; Midgley et al., 2020), due to the additional complexity associated to the possible charge compensating schemes, and the interaction of bromate impurities with the charge compensating anions. Our calculations provide a prediction of the pairing thresholds, i.e. the concentrations above which the binding energy between oppositely charged impurities at nearest-neighbour positions dominate over the entropic tendency to disassociate the impurities (at ambient temperature). We have demonstrated that the pairing is slightly stronger in aragonite than in calcite, and that if decreases down the group of alkali metals as compensating cations $(\mathrm{Li}>\mathrm{Na}>\mathrm{K})$. Assuming thermodynamic equilibrium, it can be expected that bromate substitution at ppm-level occurs with a very high degree of pairing of the bromate ion with the compensating cations in nearest-neighbour positions in the lattice.

Based on our simulations, we expect cations of smaller radii to preferentially incorporate into the carbonate structure as they cause lower degrees of lattice strain on the host. Where there is low concentration of sodium or lithium in the local aqueous environment, bromate is unlikely to be stabilised in the carbonate phase, therefore counterion abundance may be an important consideration when interpreting bromine-containing trace- 
element records. An important scenario for future investigation is charge compensation by protons, which leads to interesting chemistry as the thermodynamics becomes $\mathrm{pH}$ dependent. The solution energy calculations indicate that bromate substitution compensated by sodium or potassium cations is metastable with respect to phase separation of the impurities as solid $\mathrm{NaBrO}_{3}$ or $\mathrm{KBrO}_{3}$ phases, respectively. However, the solubility limits of bromate in calcite and aragonite are still higher than those calculated for sulphate or molybdate, so the thermodynamic driving force for bromate to separate into a competing phase is relatively weaker. This analysis suggests a larger degree of bulk substitution of bromate in calcite and aragonite compared to sulphate and molybdate.

Our findings provide structural and atomic-level insight that may the interpretation of bromine records in speleothems. Our work highlights that bromine abundance may be carbonate phase specific, i.e. relative abundances of calcite and aragonite are important considerations. Also, monovalent ions should be detected proximal to bromine impurities, where there is a strong thermodynamic preference for smaller ions. Abundance of lithium in the bromine-containing speleothem is likely to be representative of the amount of lithium in the local aqueous environment around the time of speleothem formation, which may significantly skew the detected levels of bromine compared with the deduced volcanic eruption magnitude. These are all key considerations when interpreting speleothem archive data.

\section{Acknowledgements}

S. D. Midgley acknowledges funding for his PhD studentship from the Natural Environment Research Council through the SCENARIO DTP (grant ref NE/L002566/1). This work made use of ARCHER, the UK's national high-performance computing service, via the UK's HPC Materials Chemistry Consortium, which is funded by EPSRC (EP/R029431), and of the Young supercomputer, via the UK's Materials and Molecular Modelling Hub, which is partially funded by EPSRC (EP/T022213/1).

\section{References}

Badertscher, S., Borsato, A., Frisia, S., Cheng, H., Edwards, R.L., Tüysüz, O. and Fleitmann, D. (2014) Speleothems as sensitive recorders of volcanic eruptions - the Bronze Age Minoan eruption recorded in a stalagmite from Turkey. Earth and Planetary Science Letters 392, 58-66.

Blöchl, P.E. (1994) Projector augmented-wave method. Physical Review B 50, 17953-17979.

Bobrowski, N., Hönninger, G., Galle, B. and Platt, U. (2003) Detection of bromine monoxide in a volcanic plume. Nature 423, 273-276.

Busenberg, E. and Niel Plummer, L. (1985) Kinetic and thermodynamic factors controlling the distribution of $\mathrm{SO}_{3}{ }^{2-}$ and $\mathrm{Na}^{+}$in calcites and selected aragonites. Geochimica et Cosmochimica Acta 49, 713-725.

Catlow, C. (1978) Ion distribution functions for complex solids and their application to the conductivity of glasses. physica status solidi (a) 46, 191-198.

De Choudens-Sanchez, V. and Gonzalez, L.A. (2009) Calcite and Aragonite Precipitation Under Controlled Instantaneous Supersaturation: Elucidating the Role of $\mathrm{CaCO}_{3}$ Saturation State and $\mathrm{Mg} / \mathrm{Ca}$ Ratio on Calcium Carbonate Polymorphism. Journal of Sedimentary Research 79, 363-376.

Dorale, J.A., Edwards, R.L., Calvin-Alexander Jr, E., Shen, C.C., Richards, D.A. and Cheng, H. (2004) Studies of Cave Sediments. Springer US, Boston, MA. 
Engel, A.O. and Perlmutter-Hayman, B. (1953) The Decomposition of Hypobromite and Bromite Solutions. Journal of the American Chemical Society 76, 2010-2015.

Fairchild, I.J. and Treble, P.C. (2009) Trace elements in speleothems as recorders of environmental change. Quaternary Science Reviews 28, 449-468.

Feng, X. and Redfern, S.A.T. (2018) Iodate in calcite, aragonite and vaterite $\mathrm{CaCO}_{3}$ : Insights from first-principles calculations and implications for the I/Ca geochemical proxy. Geochimica et Cosmochimica Acta 236, 351-360.

Finch, A.A., Shaw, P.A., Weedon, G.P. and Holmgren, K. (2001) Trace element variation in speleothem aragonite: potential for palaeoenvironmental reconstruction. Earth and Planetary Science Letters 186, 255-267.

Friedrich, W.L., Kromer, B., Friedrich, M., Heinemeier, J., Pfeiffer, T. and Talamo, S. (2006) Santorini eruption radiocarbon dated to $1627-1600$ BC. Science 312, 548-548.

Frisia, S., Borsato, A. and Susini, J. (2008) Synchrotron radiation applications to past volcanism archived in speleothems: An overview. Journal of Volcanology and Geothermal Research 177, 96-100.

Given, R.K. and Wilkinson, B.H. (1985) Kinetic Control of Morphology, Composition, and Mineralogy of Abiotic Sedimentary Carbonates. SEPM Journal of Sedimentary Research Vol. 55, 109-119.

González-López, J., Ruiz-Hernández, S.E., Fernández-González, Á., Jiménez, A., de Leeuw, N.H. and GrauCrespo, R. (2014) Cobalt incorporation in calcite: Thermochemistry of $(\mathrm{Ca}, \mathrm{Co}) \mathrm{CO}_{3}$ solid solutions from density functional theory simulations. Geochimica et Cosmochimica Acta 142, 205-216.

Grau-Crespo, R., de Leeuw, N.H., Hamad, S. and Waghmare, U.V. (2011) Phase separation and surface segregation in ceria-zirconia solid solutions. Proceedings of the Royal Society A: Mathematical, Physical and Engineering Sciences 467, 1925-1938.

Grau-Crespo, R., Hamad, S., Catlow, C.R.A. and Leeuw, N.H.d. (2007) Symmetry-adapted configurational modelling of fractional site occupancy in solids. Journal of Physics: Condensed Matter 19, 256201.

Hartland, A., Fairchild, I.J., Lead, J.R., Borsato, A., Baker, A., Frisia, S. and Baalousha, M. (2012) From soil to cave: Transport of trace metals by natural organic matter in karst dripwaters. Chemical Geology 304305, 68-82.

Hörmann, C., Sihler, H., Bobrowski, N., Beirle, S., Penning de Vries, M., Platt, U. and Wagner, T. (2013) Systematic investigation of bromine monoxide in volcanic plumes from space by using the GOME-2 instrument. Atmos. Chem. Phys. 13, 4749-4781.

Kerisit, S.N., Smith, F.N., Saslow, S.A., Hoover, M.E., Lawter, A.R. and Qafoku, N.P. (2018) Incorporation modes of iodate in calcite. Environmental science \& technology 52, 5902-5910.

Kresse, G. and Furthmüller, J. (1996a) Efficiency of ab-initio total energy calculations for metals and semiconductors using a plane-wave basis set. Computational Materials Science 6, 15-50.

Kresse, G. and Furthmüller, J. (1996b) Efficient iterative schemes for ab initio total-energy calculations using a plane-wave basis set. Physical Review B 54, 11169-11186.

Kresse, G. and Joubert, D. (1999) From ultrasoft pseudopotentials to the projector augmented-wave method. Physical Review B 59, 1758-1775.

Lee, C.L. and Lister, M.W. (1971) The Decomposition of Aqueous Sodium Bromite. Canadian Journal of Chemistry 49, 2822-2826.

Markgraf, S. and Reeder, R. (1985) High-temperature structure refinements of calcite and magnesite. Am. Mineral. 70, 590-600.

Marshall, D., Ghaleb, B., Countess, R. and Gabities, J. (2009) Preliminary paleoclimate reconstruction based on a 12,500 year old speleothem from Vancouver Island, Canada: stable isotopes and U-Th disequilibrium dating. Quaternary Science Reviews 28, 2507-2513.

McCarroll, D. and Loader, N.J. (2004) Stable isotopes in tree rings. Quaternary Science Reviews 23, 771-801.

Midgley, S.D., Di Tommaso, D., Fleitmann, D. and Grau-Crespo, R. (2021) Sulphur and Molybdenum Incorporation at the Calcite-Water Interface: Insights from Ab Initio Molecular Dynamics. ChemrXiv, 10.26434/chemrxiv.14546841.v14546841.

Midgley, S.D., Taylor, J.O., Fleitmann, D. and Grau-Crespo, R. (2020) Molybdenum and sulphur incorporation as oxyanion substitutional impurities in calcium carbonate minerals: a computational investigation. Chemical Geology.

Minnis, P., Harrison, E.F., Stowe, L.L., Gibson, G.G., Denn, F.M., Doelling, D.R. and Smith, W.L. (1993) Radiative Climate Forcing by the Mount Pinatubo Eruption. Science 259, 1411. 
Perdew, J.P., Burke, K. and Ernzerhof, M. (1996) Generalized gradient approximation made simple. Physical review letters 77,3865 .

Podder, J., Lin, J., Sun, W., Botis, S., Tse, J., Chen, N., Hu, Y., Li, D., Seaman, J. and Pan, Y. (2017) Iodate in calcite and vaterite: Insights from synchrotron X-ray absorption spectroscopy and first-principles calculations. Geochimica et Cosmochimica Acta 198, 218-228.

Railsback, L.B., Brook, G.A., Chen, J., Kalin, R. and Fleisher, C.J. (1994) Environmental Controls on the Petrology of a Late Holocene Speleothem from Botswana with Annual Layers of Aragonite and Calcite. SEPM Journal of Sedimentary Research Vol. 64A, 147-155.

Robock, A. (2000) Volcanic eruptions and climate. Reviews of Geophysics 38, 191-219.

Robock, A. and Free, M.P. (1995) Ice cores as an index of global volcanism from 1850 to the present. Journal of Geophysical Research: Atmospheres 100, 11549-11567.

Ruiz-Hernandez, S.E., Grau-Crespo, R., Ruiz-Salvador, A.R. and De Leeuw, N.H. (2010) Thermochemistry of strontium incorporation in aragonite from atomistic simulations. Geochimica et Cosmochimica Acta 74, 1320-1328.

Severi, M., Udisti, R., Becagli, S., Stenni, B. and Traversi, R. (2012) Volcanic synchronisation of the EPICADC and TALDICE ice cores for the last $42 \mathrm{kyr}$ BP. Climate of the Past 8, 509-517.

Sigl, M., McConnell, J.R., Layman, L., Maselli, O., McGwire, K., Pasteris, D., Dahl-Jensen, D., Steffensen, J.P., Vinther, B. and Edwards, R. (2013) A new bipolar ice core record of volcanism from WAIS Divide and NEEM and implications for climate forcing of the last 2000 years. Journal of Geophysical Research: Atmospheres 118, 1151-1169.

Smith, K.C., Fisher, T.S., Waghmare, U.V. and Grau-Crespo, R. (2010) Dopant-vacancy binding effects in Lidoped magnesium hydride. Physical Review B 82, 134109.

St Pierre, E., Zhao, J. and Reed, E. (2009) Expanding the utility of Uranium-series dating of speleothems for archaeological and palaeontological applications. Journal of Archaeological Science 36, 1416-1423.

Theys, N., Van Roozendael, M., Dils, B., Hendrick, F., Hao, N. and De Mazière, M. (2009) First satellite detection of volcanic bromine monoxide emission after the Kasatochi eruption. Geophysical Research Letters 36.

Ünal-İmer, E., Shulmeister, J., Zhao, J.-X., Tonguç Uysal, I., Feng, Y.-X., Duc Nguyen, A. and Yüce, G. (2015) An 80 kyr-long continuous speleothem record from Dim Cave, SW Turkey with paleoclimatic implications for the Eastern Mediterranean. Scientific Reports 5, 13560-13560.

Voelker, A.H.L. (2002) Global distribution of centennial-scale records for Marine Isotope Stage (MIS) 3: a database. Quaternary Science Reviews 21, 1185-1212.

Wang, Q., Grau-Crespo, R. and de Leeuw, N.H. (2011) Mixing Thermodynamics of the Calcite-Structured $(\mathrm{Mn}, \mathrm{Ca}) \mathrm{CO}_{3}$ Solid Solution: A Computer Simulation Study. The Journal of Physical Chemistry B 115, 13854-13861.

Yalcin, K., Wake, C.P., Kreutz, K.J., Germani, M.S. and Whitlow, S.I. (2007) Ice core paleovolcanic records from the St. Elias Mountains, Yukon, Canada. Journal of Geophysical Research 112, D08102-D08102.

Zielinski, G.A. (2000) Use of paleo-records in determining variability within the volcanism-climate system. Quaternary Science Reviews 19, 417-438.

Zielinski, G.A., Mayewski, P.A., Meeker, L.D., Whitlow, S., Twickler, M.S., Morrison, M., Meese, D.A., Gow, A.J. and Alley, R.B. (1994) Record of Volcanism Since 7000 B.C. from the GISP2 Greenland Ice Core and Implications for the Volcano-Climate System. Science (New York, N.Y.) 264, 948-952. 